\title{
ESTUDO DA CINÉTICA DE SECAGEM DE FERTILIZANTES EM CAMADA DELGADA: CONVECÇÃO NATURAL E FORÇADA DE AR
}

\author{
D. J. SILVA, H. PERAZZINI \\ Universidade Federal de Itajubá, Instituto de Recursos Naturais \\ E-mail para contato: perazzini@unifei.edu.br
}

\begin{abstract}
RESUMO - No presente trabalho, foram realizados estudos experimentais dos fenômenos que ocorrem durante o processo de transferência de calor e massa na secagem de fertilizantes, bem como analisada a influência das características destes materiais na cinética de secagem. Os dados experimentais permitiram a determinação de curvas de umidade em função do tempo para diferentes temperaturas, considerando a secagem com duas abordagens distintas: convecção forçada e natural. Os resultados mostraram que a variação da temperatura e a modificação no escoamento de ar influenciam diretamente o comportamento do material na secagem, bem como sua difusividade efetiva.
\end{abstract}

\section{INTRODUÇÃO}

A produção de fertilizantes no Brasil apresenta grande crescimento devido à demanda do agronegócio. Uma das operações fundamentais do processamento de fertilizantes é a secagem, pois é possível diminuir o volume do sólido, evitar empedramento e conservar os nutrientes do material. O estudo da secagem em camada delgada, por sua vez, é importante quando existem poucas informações sobre o comportamento do material frente a diferentes condições operacionais. A secagem em camada delgada significa estudar a transferência simultânea de calor e massa que se estabelece no contanto entre uma fina camada de material úmido e uma fase gasosa não saturada aquecida, frente a condições específicas de temperatura, umidade e velocidade da corrente de ar. A massa do material é, dessa forma, aferida em intervalos de tempo pré-estabelecidos. Entretanto, ainda torna-se importante contribuir com informações mais detalhadas a respeito da cinética de secagem de fertilizantes, uma vez que grande parte destes trabalhos aborda a secagem em secadores de leito móvel. $\mathrm{O}$ estudo da secagem em leito fixo e camada delgada, inclusive, contribuem com resultados que podem ser aplicados aos secadores de leitos móveis, como por exemplo, os secadores rotativos, muito empregados nas indústrias de fertilizantes. Neste trabalho foi dado inicio aos estudos de secagem de fertilizante em camada delgada por meio de experimentos de secagem com convecção forçada e natural, por meio da obtenção de dados de umidade em função do tempo para diferentes temperaturas do.

\section{TRATAMENTO DOS DADOS}

Os dados de umidade em função do tempo foram ajustados com base no modelo difusivo, segundo a solução analítica representada pela Equação (1) (CRANK, 1975). São 
válidas as seguintes hipóteses: transferência de umidade unidimensional, conteúdo de umidade inicial uniforme, sem encolhimento, processo isotérmico, propriedades físicas do sólido e difusividade efetiva constante ao longo da secagem.

$$
X^{*}=\frac{\bar{X}-X_{e q}}{X_{0}-X_{e q}}=2 \sum_{n=1}^{\infty} \frac{B i_{m}{ }^{2}}{\lambda_{n}{ }^{2}\left(\lambda_{n}{ }^{2}+B i_{m}{ }^{2}+B i_{m}\right)} \exp \left(-\lambda_{n}^{2} \frac{D_{e f f}}{4 L^{2}} t\right)
$$

Para a Equação (2), as raízes $\lambda_{\mathrm{n}}$ são determinadas pela seguinte equação transcendental:

$$
B i_{m}=\lambda_{n} \operatorname{tg}\left(\lambda_{n}\right)
$$

A difusividade efetiva $\left(D_{\text {eff }}\right)$ é usualmente tratada pela literatura como função da temperatura, segundo uma correlação do tipo Arrhenius:

$$
D_{\text {eff }}=D_{0} \exp \left(-\frac{E_{a}}{R T}\right)
$$

Entretanto, foi demonstrado por Kiranoudis et al. (1995) que o fator de Arrhenius $\mathrm{D}_{0} \mathrm{e}$ a energia de ativação para a difusão de umidade $\left(E_{a}\right)$ são propriedades fortemente correlacionadas. Entende-se, assim, que o valor estimado da difusividade efetiva é devido a uma combinação destes dois parâmetros. Em estudos envolvendo cinética química, Mezaki e Kittrell (1967) verificaram a necessidade de reparametrização da correlação de Arrhenius, uma vez verificada a não linearidade dos parâmetros $D_{0}$ e $E_{a}$ e resultados inadequados na estimação. Freire et al. (1995) efetuaram a reparametrização, resultando na seguinte transformação da Equação (3). A substituição da Equação (4) na Equação (1) e fazendo T* = $273,15 \mathrm{~K}$, resulta em um modelo difusivo com novos graus de liberdade e um novo conjunto de parâmetros a serem estimados.

$$
D_{\text {eff }}=\exp (\beta) \exp \left[-\left(\frac{1}{T}-\frac{1}{T^{*}}\right) \exp (\gamma)\right]
$$

\section{MATERIAIS E MÉTODOS}

\subsection{Material particulado}

O fertilizante utilizado nos experimentos foi o superfosfato simples fabricado pela Heringer. $\mathrm{O}$ fertilizante foi previamente umidificado para garantir que a umidade estivesse presente em todo material, externamente e internamente, de modo que os dados obtidos na secagem fossem efetivos. Para umidificação, o material foi mergulhado em um recipiente com água e permaneceu por 48 horas. As propriedades físicas e estruturais do fertilizante foram determinadas por meio da caracterização das partículas e foram obtidos o diâmetro médio da partícula de $2 \mathrm{~mm}$ por peneiramento, porosidade de 0,44 por gravimetria, massa específica 
real de $1,88 \mathrm{~g} / \mathrm{cm}^{3}$ por picnometria líquida, esfericidade de 0,76 por análise de imagens e poros com diâmetro entre $5-10 \mathrm{~nm}$, majoritariamente, determinado pelo método B.E.T.

\subsection{Unidade experimental de secagem}

Para a determinação da cinética de secagem, foram utilizadas duas unidades experimentais, um secador de leito fixo, apresentado na Figura 1, para secagem com convecção forçada e uma estufa a vácuo, operando nas mesmas condições do secador, para secagem com convecção natural.

Figura 1 - Esquema da unidade experimental de secagem: (1) soprador; (2) resistência elétrica; (3) túnel de vento; (4) termômetro de mercúrio; (5) material particulado.

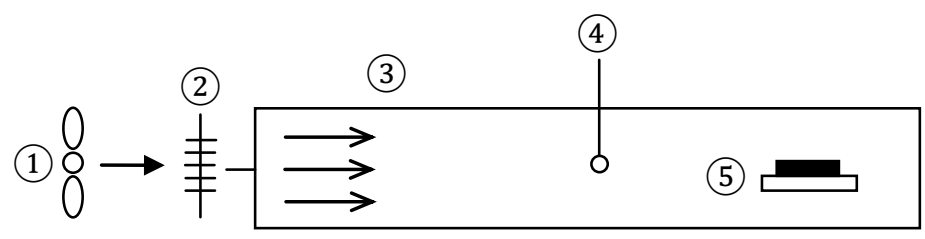

\subsection{Metodologia experimental}

Para o estudo da secagem com convecção forçada, ligou-se a ventoinha do secador, ajustou-se a temperatura e esperou-se que o equipamento entrasse em equilíbrio térmico. Posteriormente, uma camada delgada previamente pesada, foi colocada no túnel. O material foi pesado em balança semianalítica em intervalos de tempo pré-determinados e quando a massa do fertilizante não variou com o tempo, assumiu-se que o equilíbrio entre as fases foi atingido. Para averiguar o procedimento, o material foi colocado em uma estufa a $105^{\circ} \mathrm{C}$ por 24 horas e por fim foi colocado em um dessecador para resfriar. Após esse período, o material foi retirado e pesado novamente para aferição da massa. Para o estudo da convecção natural, ligou-se a estufa, ajustou-se a temperatura desejada e repetiram-se os procedimentos. Em ambos os equipamentos foram realizadas secagens com temperaturas a 50 e $70^{\circ} \mathrm{C}$.

\section{RESULTADOS}

\subsection{Estudos de secagem em convecção natural}

A comparação típica entre dados observados e preditos pelo modelo difusivo para convecção natural são apresentados na Figura 2 (a). Como é possível verificar, o modelo prevê satisfatoriamente os dados observados experimentalmente. $\mathrm{O}$ aumento da temperatura, por sua vez, ocasiona um incremento no potencial de secagem, favorecido pela maior agitação das moléculas de água na temperatura mais elevada. Resultados similares também foram verificados para outros materiais inorgânicos (PERAZZINI, 2014). Em uma análise da Figura 2 (b), a qual apresenta as curvas típicas de taxa de secagem, constata-se que a secagem ocorre em três estágios. Inicialmente, observa-se que nas primeiras etapas a taxa de secagem é constante, pois nesta etapa, somente a água superficial evapora. A partir da umidade crítica, a influência da temperatura, devido ao aumento da pressão de vapor, é mais evidenciada, iniciando-se o processo de secagem no interior das partículas, o primeiro período de taxa de 
secagem decrescente, caracterizando a difusão de líquido. Por fim, taxa de secagem decresce exponencialmente, indicando o escoamento de vapor no interior dos poros.

Figura 2 - Convecção natural: (a) cinética de secagem; (b) taxa de secagem.
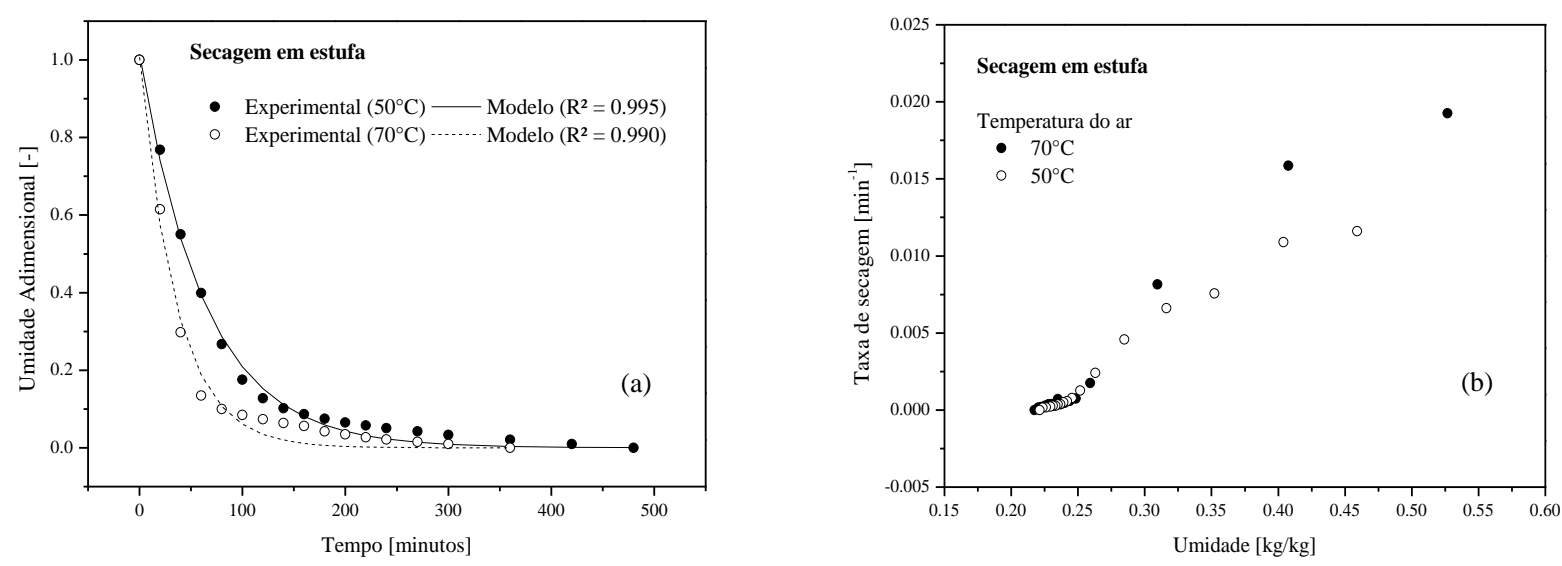

\subsection{Estudos de secagem em convecção forçada}

Com base nos resultados apresentados na Figura 3 (a) e (b), ao contrário do observado nos experimentos de convecção natural, a influência da temperatura do ar na cinética de secagem dos fertilizantes mostrou-se pouco preponderante. No entanto, os baixos valores de desvio padrão 0,26 e de variância 0,07 sugerem que os dados de umidade em função do tempo são reprodutíveis. Também ao contrário do observado para a secagem em estufa, foi verificado a presença de um período inicial de ajuste de temperatura, caracterizado pelo aquecimento inicial do sólido, aumentando rapidamente a taxa de secagem.

Figura 3 - Convecção forçada: (a) cinética de secagem; (b) taxa de secagem.
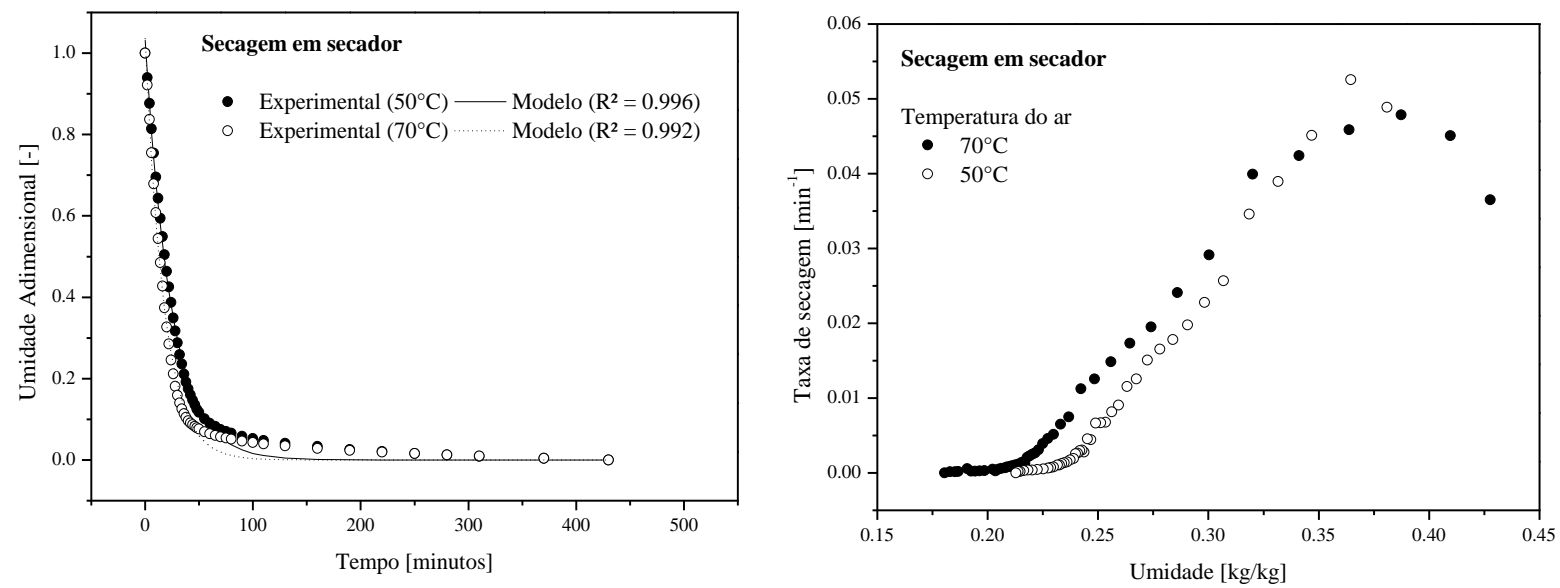

\subsection{Comparação entre os métodos de secagem}

Tendo realizado os experimentos, foi feita uma comparação entre os métodos convectivos utilizados apresentados na Figura 4. Como esperado, para ambas as temperaturas a secagem se inicia com comportamento parecido para ambos os equipamentos. Com o 
decorrer do tempo, a secagem com convecção forçada ocorre mais rapidamente que na convecção natural, pois a água no interior da partícula começa a evaporar então além da mudança de temperatura, a força eletromotriz na convecção forçada propicia uma velocidade no escoamento que irá interferir na pressão de vapor e irá definir o comportamento do material na secagem. Na estufa não há velocidade significativa de escoamento de ar, fazendo com que a secagem seja mais lenta, apresentando a vantagem de obterem-se com maior facilidade condições termodinâmicas constantes. Quando as partículas se encontram com reduzido conteúdo de umidade, o comportamento na secagem volta a ser parecido para ambos os procedimentos até que assuma regime permanente e a umidade adimensional seja nula.

Figura 4 - Comparação entre os métodos $50^{\circ} \mathrm{C}$ simulado pelo modelo difusivo.

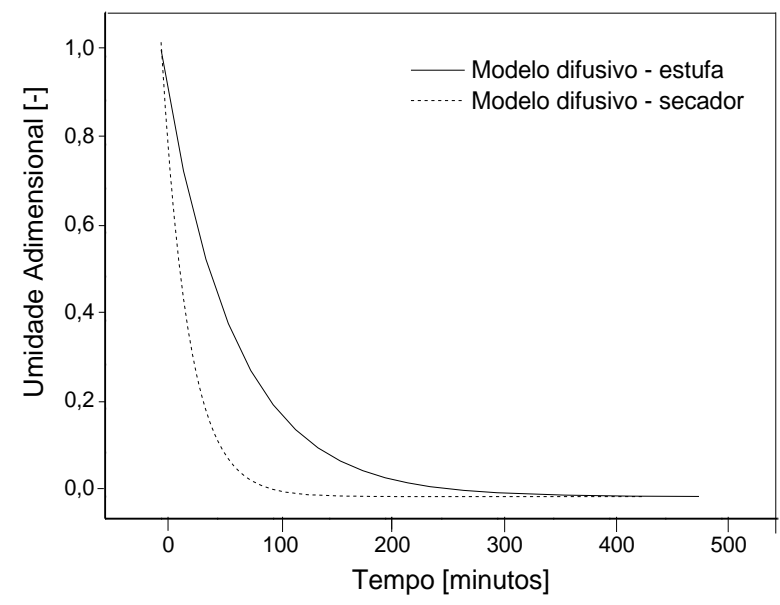

Por fim, foi possível determinar o coeficiente de difusividade efetivo do material e a energia de ativação, apresentados na Tabela 1. A energia de ativação é considerada uma barreira a ser vencida para que a difusão ocorra. Dessa forma, quanto menor a energia de ativação, maior será a facilidade de movimentação da água. É possível verificar também que o aumento da temperatura aumenta a difusividade efetiva, pois diminui a viscosidade da água e aumenta a vibração das moléculas de água no interior das partículas, de modo que a energia de ativação diminua e a difusividade para temperaturas mais altas seja maior. No caso da presença da velocidade no escoamento, para a convecção forçada a difusividade também aumenta em relação à convecção natural, pois o aumento da velocidade também aumenta a taxa de secagem e reduz a energia de ativação.

Tabela 1: Estimativas do modelo difusivo reparametrizado.

\begin{tabular}{|l|c|c|c|c|c|c|}
\hline \multicolumn{1}{|c|}{$\mathrm{T}\left[{ }^{\circ} \mathrm{C}\right]$} & $\beta[-]$ & $\gamma[-]$ & $\mathrm{Bi}[-]$ & $\mathrm{D}_{0}\left[\mathrm{~m}^{2} / \mathrm{s}\right]$ & $\mathrm{D}_{\text {eff }}\left[\mathrm{m}^{2} / \mathrm{s}\right]$ & $\mathrm{Ea}[\mathrm{kJ} / \mathrm{mol}]$ \\
\hline 50 (Secador) & $-14,02$ & 7,56 & 9,67 & $9,02 \times 10^{-4}$ & $2,40 \times 10^{-6}$ & 15,92 \\
\hline 70 (Secador) & $-14,04$ & 7,55 & 10,02 & $8,49 \times 10^{-4}$ & $3,30 \times 10^{-6}$ & 15,83 \\
\hline 50 (Estufa) & $-15,22$ & 7,70 & 13,90 & $8,56 \times 10^{-4}$ & $8,68 \times 10^{-7}$ & 18,52 \\
\hline 70 (Estufa) & $-15,03$ & 7,69 & 12,63 & $9,42 \times 10^{-4}$ & $1,54 \times 10^{-6}$ & 18,31 \\
\hline
\end{tabular}




\section{CONCLUSÕES}

O presente trabalhado se propôs a estudar a secagem de fertilizantes em secador de leito fixo e camada delgada frente a diferentes condições operacionais. Foram determinadas as principais propriedades físicas e estruturais dos materiais estudados. Tais propriedades foram importantes para compreender melhor a secagem dos fertilizantes a ser determinada em etapa posterior ao trabalho. Dessa forma, foi possível conhecer o material para melhor entendimento de sua cinética de secagem. A partir dos dados de cinética de secagem obtidos experimentalmente foi possível inferir na complexidade da secagem dos materiais porosos. É possível concluir que a difusão interna de umidade controla o processo de secagem, caracterizada por elevados números de Biot, sendo que, por meio das taxas de secagem, a difusão interna deve-se à movimentação de umidade na fase líquida e vapor. Informações como a difusividade efetiva e a energia de ativação foram obtidas e constatou-se que para temperaturas mais altas a difusividade no material foi maior assim como na secagem com convecção forçada. A energia de ativação, por sua vez, foi menor para altas temperaturas e para a secagem convectiva, indicando uma facilidade na mobilidade das moléculas de água para estas condições. Tais conclusões possibilitam direcionamentos a problemas de engenharia, como por exemplo, escolha de condições operacionais e projetos adequados de secadores, a fim de maximizar a eficiência térmica e energética da secagem.

\section{NOMENCLATURA}

$\mathrm{Bi}_{\mathrm{m}}$ : Número de Biot para transferência de massa [-]

$\mathrm{D}_{\text {eff: }}$ Difusividade efetiva de umidade $\left[\mathrm{m}^{2} / \mathrm{s}\right]$

$\mathrm{D}_{\mathrm{p}}$ : Diâmetro da partícula

$\mathrm{D}_{0}$ : Fator pré-exponencial de Arrhenius $\left[\mathrm{m}^{2} / \mathrm{s}\right]$

$\mathrm{E}_{\mathrm{a}}$ : Energia de ativação $[\mathrm{kJ} / \mathrm{mol}]$

L: Espessura do sólido [m]

$\mathrm{n}$ : Número de termos da série infinita [-]

$\mathrm{R}$ : Constante dos gases ideais $[\mathrm{kJ} / \mathrm{mol} \cdot \mathrm{K}]$

t: Tempo de secagem [s]

T: Temperatura do ar $[\mathrm{K}]$

$T^{*}$ : Temperatura de referência $[K]$
$\mathrm{X}$ : Umidade em base seca $[\mathrm{kg} / \mathrm{kg}]$

$X_{\text {eq: }}$ Umidade de equilíbrio $[\mathrm{kg} / \mathrm{kg}]$

$\mathrm{X}_{0:}$ Umidade inicial $[\mathrm{kg} / \mathrm{kg}]$

$\mathrm{X}^{*}$ : Umidade adimensional [-]

$\overline{\mathrm{X}}$ : Umidade média $[\mathrm{kg} / \mathrm{kg}]$

$\beta$ : Parâmetro da equação reparametrizada que representa a variação de $\mathrm{D}_{\text {eff }} \operatorname{com} \mathrm{T}[-]$ $\varepsilon$ : Porosidade

$\Phi$ : Esfericidade

$\gamma$ : Parâmetro da equação reparametrizada que representa a variação de $\mathrm{D}_{\text {eff }}$ com $\mathrm{T}$ [-] $\rho$ : Massa específica

$\lambda$ : Raízes da equação transcendental [-]

\section{REFERÊNCIAS}

BARROZO, M.A.S., SARTORI, D.J.M., FREIRE, J.T., 2004. A study of the statistical discrimination of the drying kinetics equations. Food Bioprod. Process. 82, 219-225.

CRANK, J. The mathematics of diffusion. 2. ed. Oxford: Claredon Press, 1975. 414 p.

FERNANDES, N. J. 2008. Estudo da fluidodinâmica e da secagem de um secador rotatório da indústria de fertilizantes. 90 p. Tese (Mestrado em Engenharia Química) - Faculdade de Engenharia Química, Universidade Federal de Uberlândia, Uberlândia, 2008. 
KIRANOUDIS, C. T.; MAROULIS, Z.B.; MARINOS-KOURIS, D. 1995. Heat and mass transfer model building in drying with multi-response data. International Journal of Heat and Mass Transfer, 38(3), 463-480.

MEZAKI, R.; KITTRELL, J.R. Parametric sensitivity in fitting nonlinear kinetic models. Industrial Engineering and Chemistry 1967, 59 (5), 63-69.

PERAZZINI, H. 2014. Secagem de Sólidos Porosos Granulares. 170 p. Tese (Doutorado em Engenharia Química) - Departamento de Engenharia Química, Universidade Federal de São Carlos, São Carlos, 2014. 